\title{
Use of Load Shedding Scheme to Increase the Capacity Limit on the Single Largest Generator
}

\author{
C.K.S.Hapuarachchi, M.D.M.C.Gunawardena, D.P.Haputhanthri, I.G.C.Harshana, \\ J.R.Lucas and W.D.A.S. Wijayapala
}

\begin{abstract}
This paper examines the stability of the Sri Lankan power system with the emergence of the large coal power plants. Such coal power plants are being introduced to Sri Lanka with the aim of bringing down electricity costs. Sri Lanka at present, has a maximum peak demand of around 2100 MW with an off peak demand of being a low of nearly $900 \mathrm{MW}$ during the early hours of the morning. It is in such a backdrop that a large coal power plant of 300MW has been introduced to Sri Lanka intended to run as base load. Due to reasons of current practice, the capacity limit of the single largest generator is set at $20 \%$ of the instantaneous system demand. Thus underutilization of the coal power plant would occur during the off peak hours.
\end{abstract}

This paper looks into ways of increasing the $20 \%$ limit up to an amount such that the coal power plant could be used to full capacity even during off peak hours. The $220 \mathrm{kV}$ and part of the $132 \mathrm{kV}$ transmission system of Sri Lankan power system has been modeled on PSCAD software, taking into account the various parameters of power stations and transmission lines. With the use of the software, contingency situations have been analysed and the load shedding scheme currently being used by the CEB is revised such that the limit placed on the single largest generator could be increased to $25 \%$ of the current demand.

Keywords: Capacity Limit, Load Shedding

\section{Introduction}

Since electricity was introduced to Sri Lanka way back in 1895, Sri Lanka has been showing a gradual, and at times major, increase in electricity demand which averages to about $8 \%$ per annum. In 2011 Sri Lanka had a load curve as shown in Figure 1, with a maximum peak demand of nearly $2000 \mathrm{MW}$ and a off peak demand of $900 \mathrm{MW}$. The load curve was estimated based on the actual load curve of 17 March 2010 and the growth rate predicted by the Ceylon Electricity Board (CEB).

Sri Lanka has depended on large hydro power stations in the past to cater to most of the electricity needs. With large hydro power capacities reaching its peak, and oil-fired thermal options being expensive, the nation has been looking for other cheap electricity generating options to cater to the ever increasing demand [1]. To ease the situation, a coal power plant with an eventual capacity of $900 \mathrm{MW}$ is being built in Noracholai, Puttlam [2]. As the first part of this, a $300 \mathrm{MW}$ plant has been completed in 2011 giving a net output of $285 \mathrm{MW}$ to the System. The coal power plants at Norochchalai are being built to cater to the base load power requirements.
Due to reasons of system stability, caused by the mismatch between supply and demand when a large generator trips [3], the System Control Centre of the CEB has limited the generation, at a given instant, from any single generating to $20 \%$ of the total demand [4]. Thus the 300MW Coal power plant cannot be utilized to generate more than $180 \mathrm{MW}$ during off-peak hours. Not being able to utilize the cheap coal power of $285 \mathrm{MW}$ as base load fully, it becomes necessary to dispatch expensive oilbased power generation to meet the deficit that

C.K.S. Hapuarachchi, B.Sc. Eng(Hons.), Temponary Instructor, University of Monatuwa

M.D.M.C.Gunawardena, B.Sc. Eng(Hons.)

D.P.Haputhanthri, B.Sc. Eng(Hons.), Design Engineer, LTL

Transformers(Pot) Ltd

I.G.C.Harshana, B.Sc. Eng(Hons.), Electrical Engineer, Jay Jay

Mills (Bangladesh) Pot Ltd

Eng. (Prof.) J.R. Lucas, B.Sc. Eng.(Ceylon), MSc (Manch), PhD (Manch), FIE(Sri Lanka), FIEE, IPEng., Senior Professor of Electrical Engineering, Department of Electrical Enginecring.

University of Moratuon.

Eng. W.D. A. S. Wijayapala, B.Sc. Eng.(Hons), MEng,

IntPEng, CEng, FIE(Sri Lanka), Senior Lecturer, Department of

Electrical Engineering, University of Moratuan. 


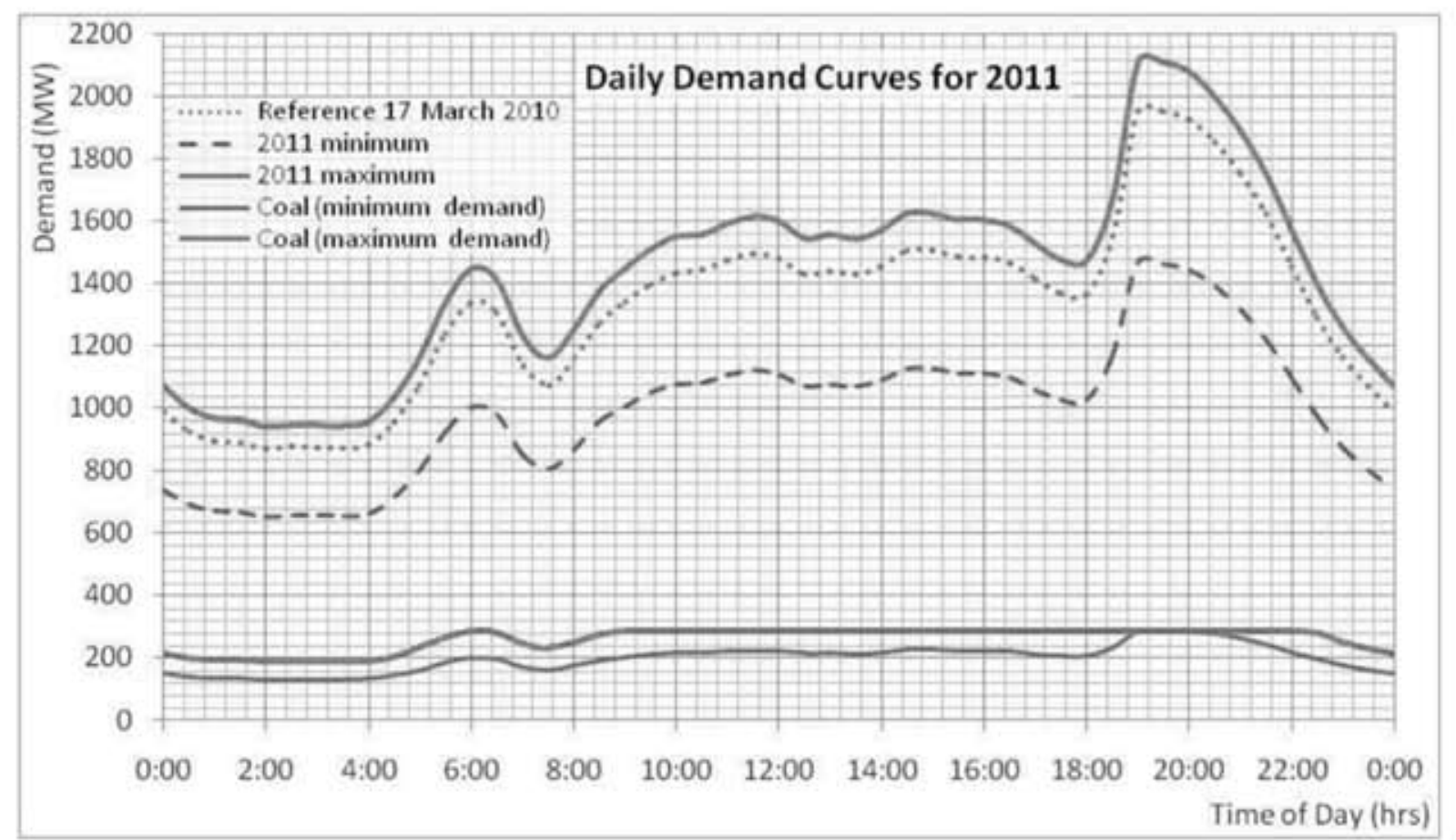

Figure 1 - Estimated daily demand curve and the estimated coal power usage when demand is at maximum and minimum. Extracted from [5]

could have been supplied by the coal power plant if not for the $20 \%$ limit imposed by stability issues.

\section{Simulation of the Sri Lankan Power Grid}

The Power System Computer Aided Design (PSCAD) software was used in modeling the Sri Lankan Power System. Actual parameters from the Ceylon Electricity Board were used in the system simulation [5].
Simplifications were made, by combining parts of the power system, to make the analysis compact. However, all the important busbars and transmission lines were retained in the model with actual parameters so that the representation gives fairly accurate results [TP,GP], especially near the Norochcholai busbar.

The overall assessment however may not be indicative of the individual details of the parts combined.

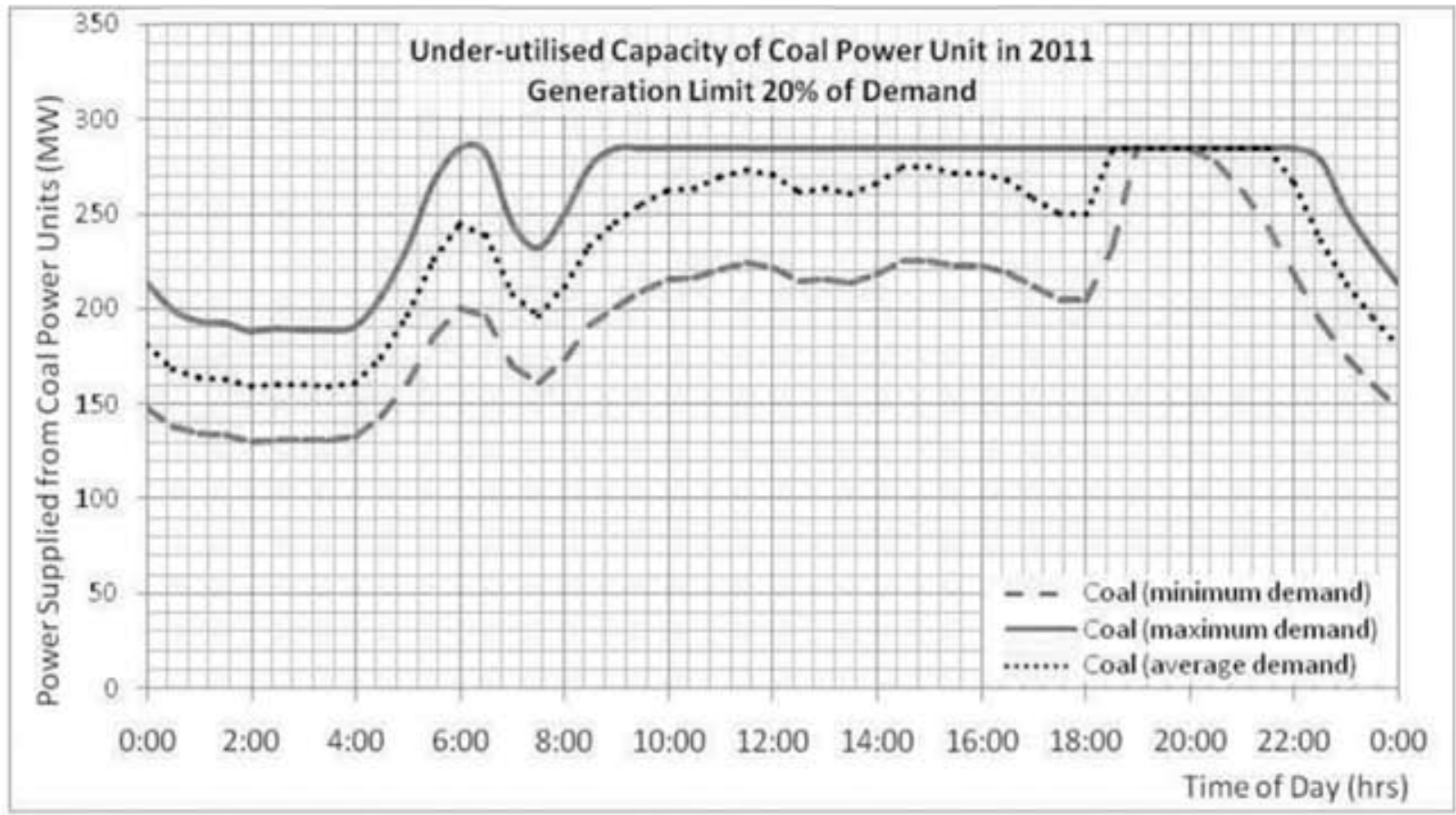

Figure 2 - Under Utilization Capacity of Coal Power Plant at present 20\% Limit - Extracted from [5] 
As the PSCAD software needs initializing data, these were obtained from a simulation done on a similar system on the PSSE software.

Transient behavior of the system, when the generator units are tripped, was analyzed by tripping diverse generators with diverse contributions to the system demand.

\section{Methodology}

Due to the $20 \%$ limit placed on the single largest generator, under utilization of the Norochcholai coal power plant occurs during the off peak hours as illustrated in figure 2 .

To decide on the most appropriate simulation moment the off peak period was selected, where the capacity limit of the coal power plant could be around the newly desired $25 \%$ of the system demand.

System Inertia $\mathrm{H}_{\text {system }}$ plays a big role in system stability [2],

$$
H_{\text {sysem }}=\frac{\sum H_{1} s_{i}}{\sum s_{i}}
$$

where, $\mathrm{H}_{\mathrm{i}}$ is inertia constant of the $\mathrm{i}^{\text {th }}$ machine, $\mathrm{S}_{i}^{\text {th }}$ is the apparent power of the $\mathrm{i}^{\text {th }}$ machine.

As

$$
\frac{d f}{d t}=-\frac{\Delta \mathrm{P}}{2 H}
$$

where, $\Delta \mathrm{P}$ is the Generation loss [3].

In effect, the lowest system inertia too occurs during the off peak hours when the system is mainly loaded with low inertia thermal power plants and less with hydro power plants which tend to have higher inertia constants. Thus this simulation has been carried out taking into account the worst case scenario for the system and thus the system would react better at other generation mixes.

\section{Load Shedding Simulation and Result}

Although having spinning reserves to cater to the total of the largest generator plant would assist in maintaining power system stability during a restoration subsequent to the tripping of the largest generator, the maintenance of such high spinning reserves is not only expensive but would not act fast enough to prevent a catastrophe. Thus the feasible solution is to recover the system through a load shedding scheme.
To come up with a load shedding scheme which operates depending on both frequency levels and rate of change of frequency (df/dt), frequency variations when various generators are tripped are taken into consideration. The behavior of frequency $f$ and $(d f / d t)$ are further analyzed for diverse situations to determine the actual loss occurring in the system. Depending on those results the loads that have to be taken out from the system by the load shedding scheme were determined.

By adopting such a method, unnecessary shedding of loads can be prevented and the frequency over shoots can be minimized. Also, when the system is subjected to a severe contingency situation, a comparatively large load can be shed considering the $\mathrm{df} / \mathrm{dt}$ at the very beginning where small size of load shed might jeopardize the system's chance of recovery.

Load shedding is designed in stages to minimize the possible frequency overshoot and the inconvenience to the public where the probability of a black out is reduced at the same time.

To make the disturbance to the public minimum, initial stages are kept sufficiently small. This was achieved by analyzing the power system behavior under various conditions by adjusting the time constants and the percentage of load to be shed when the system is simulated with such contingency situations.

Further, the load shedding could be more effective when the rate of change of frequency too is included in the scheme. In such an instance, a large generator tripping could be identified quickly with the levels of (df/dt) measured with respect to generator tripping's of various magnitudes.

Taking into account the $(\mathrm{df} / \mathrm{dt})$ characteristics, and the present load shedding scheme used at the Ceylon Electricity Board, the study has come up with a new load shedding scheme which could withstand a sudden $25 \%$ generation loss and keep the system stable.

Table 1 shows the generator loss as a percentage of the total demand and the ensuing rate of change of frequency arising from the loss of that generation. 


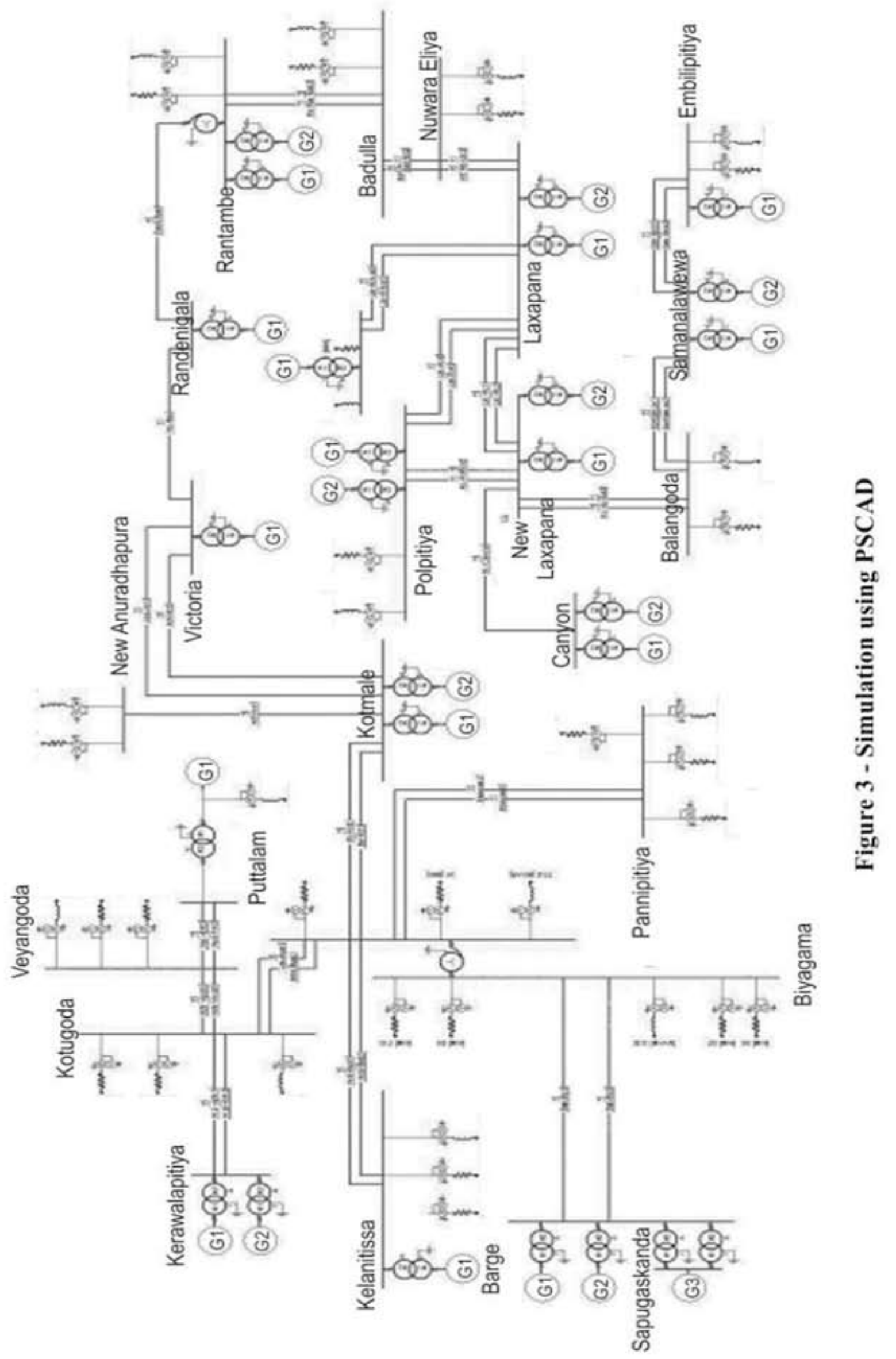


Table 1 - df/dt behavior on Generator loss percentage

\begin{tabular}{|c|c|}
\hline Generator Loss \% & $\mathrm{df} / \mathrm{dt}(\mathrm{Hz} / \mathrm{s})$ \\
\hline 4.04 & 0.22 \\
\hline 11.62 & 0.60 \\
\hline 15.33 & 0.76 \\
\hline 19.15 & 0.96 \\
\hline 26.00 & 1.23 \\
\hline
\end{tabular}

The new load shedding scheme has revised the (df/dt) graded ratings. Also the initial load shedding percentagewise is slightly higher such that large generator trippings are detected fast. Frequency over shoots when small generators trip too have been minimized in coming up with the final load shedding scheme.

The frequency responses simulated when different percentages of generation are lost using the new load shedding scheme in our simulated model is illustrated in figures 4 to 9 . These graphs are intended to show the recovery of the frequency dip due to the loss of the corresponding generation by the implementation of the new load shedding scheme.

In the case shown in Figure 4, with a loss of $1.13 \%$ of the generation, the system stabilizes with the operation of just the first stage of load shedding, (df/dt) is measured at $0.07 \mathrm{~Hz}$.

Table 2 shows the proposed load shedding scheme in order to increase the $20 \%$ generation to $25 \%$ keeping the system stable. In particular, the tripping criteria utilizes the $\mathrm{df} / \mathrm{dt}$ rates obtained in the study (Table 1).

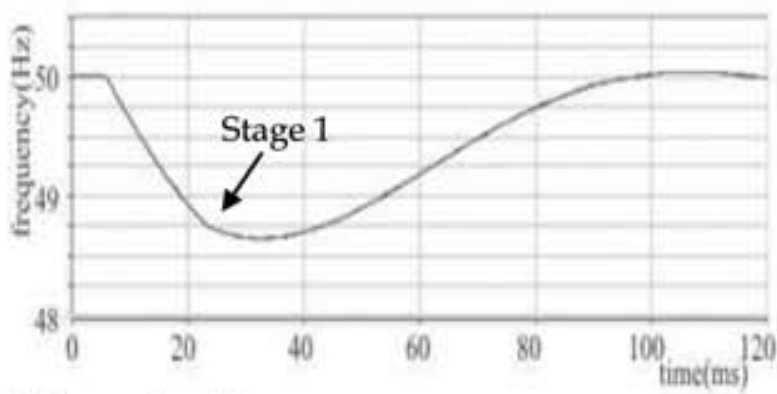

Figure 4 - Frequency response to generator loss of $1.13 \%$

In the case shown in Figure 5, with $4.04 \%$ loss of generation, stages 1,2 and 3 are activated and the (df/dt) is measured at $0.22 \mathrm{~Hz} / \mathrm{s}$.

System stabilizes with the operation of 5 stages of load shedding in the case shown in Figure 6 and the $(\mathrm{df} / \mathrm{dt})$ is measured at $0.62 \mathrm{~Hz} / \mathrm{s}$.

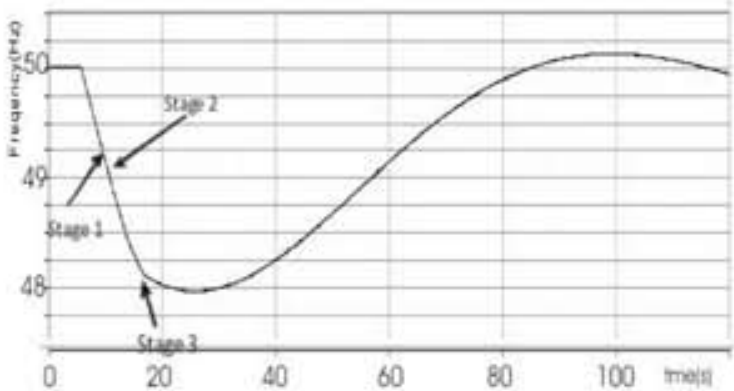

Figure 5 - Frequency response to generator loss of $4.04 \%$

Table 2 - Desired load shedding scheme for $25 \%$ generator limit

\begin{tabular}{|c|c|c|c|}
\hline Stage & $\begin{array}{c}\% \text { Load } \\
\text { to be } \\
\text { tripped }\end{array}$ & Load Shed & $\begin{array}{l}\text { Tripping } \\
\text { Criteria }\end{array}$ \\
\hline 1 & 0.25 & $\begin{array}{l}0.25 \% \text { Load on } \\
\text { frequency } \\
\text { based tripping }\end{array}$ & $\begin{array}{l}48.75 \mathrm{~Hz} \& \\
\mathrm{t}=100 \mathrm{~ms}\end{array}$ \\
\hline 2 & 0.88 & $\begin{array}{l}0.88 \% \text { Load on } \\
\text { frequency } \\
\text { based tripping }\end{array}$ & $\begin{array}{l}48.25 \mathrm{~Hz} \& \\
\mathrm{t}=500 \mathrm{~ms}\end{array}$ \\
\hline \multirow[b]{2}{*}{3} & \multirow[b]{2}{*}{3.12} & $\begin{array}{l}1.56 \% \text { Load on } \\
\text { frequency } \\
\text { based tripping }\end{array}$ & \multirow{2}{*}{$\begin{array}{l}48.25 \mathrm{~Hz} \& \\
\mathrm{t}=1000 \mathrm{~ms} \\
\text { OR } 49 \mathrm{~Hz} \\
\& \\
\mathrm{df} / \mathrm{dt}=0.9\end{array}$} \\
\hline & & $\begin{array}{l}1.56 \% \text { Load on } \\
\text { frequency } \\
\text { based }+\mathrm{df} / \mathrm{dt} \\
\text { based tripping }\end{array}$ & \\
\hline \multirow[b]{2}{*}{4} & \multirow[b]{2}{*}{6.54} & $\begin{array}{l}3.27 \% \text { Load on } \\
\text { frequency } \\
\text { based tripping }\end{array}$ & \multirow{2}{*}{$\begin{array}{l}47.9 \mathrm{~Hz} \& \\
\mathrm{t}=1200 \mathrm{~ms} \\
\text { OR } 49 \mathrm{~Hz} \\
\& \\
\mathrm{df} / \mathrm{dt}=0.9\end{array}$} \\
\hline & & $\begin{array}{l}3.27 \% \text { Load on } \\
\text { frequency } \\
\text { based }+\mathrm{df} / \mathrm{dt} \\
\text { based tripping }\end{array}$ & \\
\hline \multirow[b]{2}{*}{5} & \multirow[b]{2}{*}{5.74} & $\begin{array}{l}2.87 \% \text { Load on } \\
\text { frequency } \\
\text { based tripping }\end{array}$ & \multirow{2}{*}{$\begin{array}{l}47.5 \mathrm{~Hz} \& \\
\mathrm{t}=0.0 \mathrm{~ms} \\
\text { OR } 49 \mathrm{~Hz} \\
\& \\
\mathrm{df} / \mathrm{dt}=0.9\end{array}$} \\
\hline & & $\begin{array}{l}2.87 \% \text { Load on } \\
\text { frequency } \\
\text { based }+\mathrm{df} / \mathrm{dt} \\
\text { based tripping }\end{array}$ & \\
\hline 6 & 1.63 & $\begin{array}{l}1.63 \% \text { Load on } \\
\text { df/dt based } \\
\text { tripping }\end{array}$ & $\begin{array}{l}49 \mathrm{~Hz} \& \\
\mathrm{df} / \mathrm{dt}=0.7\end{array}$ \\
\hline 7 & 7.36 & $\begin{array}{l}7.36 \% \text { Load on } \\
\text { df/dt based } \\
\text { tripping }\end{array}$ & $\begin{array}{l}49 \mathrm{~Hz} \& \\
\mathrm{df} / \mathrm{dt}=0.9\end{array}$ \\
\hline 8 & 7.74 & $\begin{array}{l}7.74 \% \text { Load on } \\
\text { df/dt based } \\
\text { tripping }\end{array}$ & $\begin{array}{l}49 \mathrm{~Hz} \& \\
\mathrm{df} / \mathrm{dt}=1.1\end{array}$ \\
\hline
\end{tabular}

Stages 6,7 and 8 does not depend on $t$. 


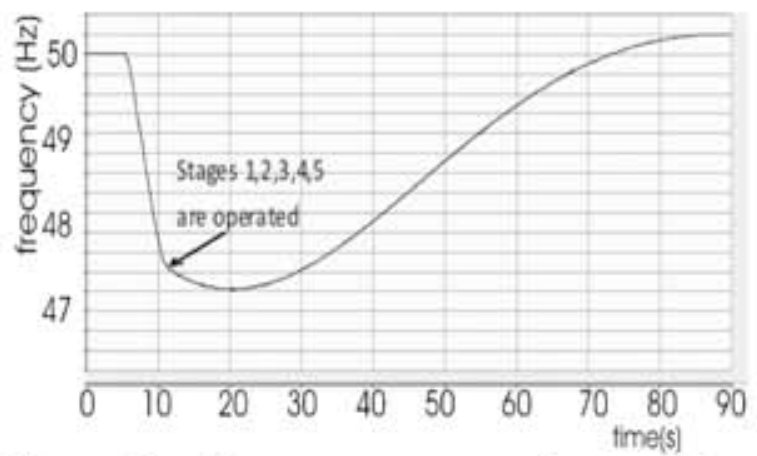

Figure 6 - Frequency response to generator loss of $11.8 \%$

All 6 stages of frequency dependent load shedding has occurred in the case shown in Figure 7 and the $(\mathrm{df} / \mathrm{dt})$ is at $0.76 \mathrm{~Hz} / \mathrm{s}$.

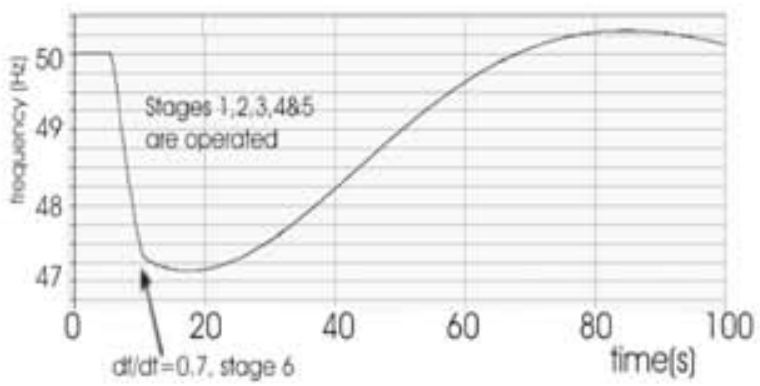

Figure 7 - Frequency response to the generator loss of $15.33 \%$

In the case shown in Figure $8,16.69 \%$ of load is shed, initiating the first rate of change of frequency load shedding and also the first two stages of frequency dependent load shedding. The $(\mathrm{df} / \mathrm{dt})$ is measured at $0.96 \mathrm{~Hz} / \mathrm{s}$.

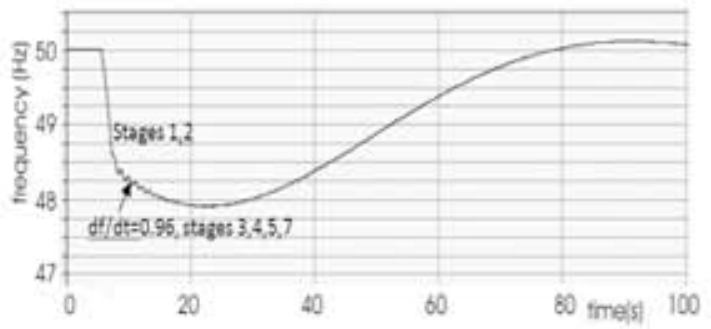

Figure 8 - Frequency response to the generator loss of $19.15 \%$

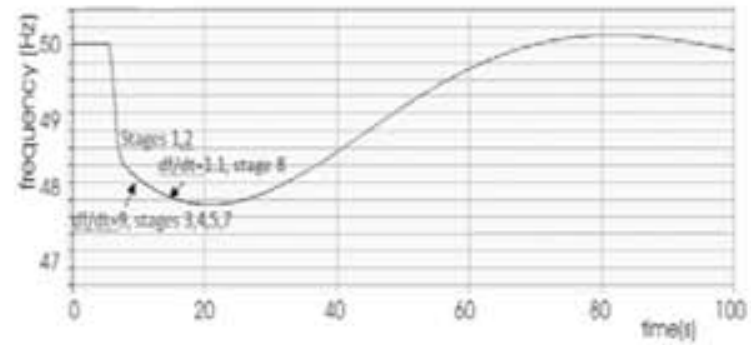

Figure 9 - Frequency response to a generator loss of $26.00 \%$.
In this final case shown in Figure 9, the largest generator loss amounting to $26 \%$ of the current load caused a measured (df/dt) of $1.23 \mathrm{~Hz} / \mathrm{s}$. In this case after activation of load schedding stages $1 \& 2$, stages $3,45,7$ and 8 have been activated based on rate of change of frequency decisions in stabilizing the system.

\section{Conclusion}

The present study carried out in 2011, has studied the effects of non-utilisation of the cheap coal power resources, due to stability issues, during low demand situations with the size of generation by a single unit being limited to $20 \%$ of total instantaneous demand.

As having spinning reserves equal to the largest generator plant alone would not solve the stability issue, a scheme to recover the system through load shedding has been proposed.

The analysis carried out into the increase in Generation limit of the Sri Lankan power system from the present limit of $20 \%$ has brought out the fact that $25 \%$ limit could be attained with the proposed, amended load shedding scheme without the loss of stability.

Also, although an increased generation limit could be vital in realizing financial benefits in the near future, with the ever increasing demand growth this underutilization would not be a problem in the longer run.

\section{References}

1. "CEB Statistical Digest Report 2011", CEB, Colombo, 2011.

2. "Long Term Generation Expansion Plan 2009. 2022, Transmission \& Generation Planning Branch, CEB, February 2009.

3. Kundur P. "Power System Stability and Control", McGraw Hill, 1994

4. Siyambalapitiya T, Udawatta L, Indatissa A, Perera S, Botheju N, Imbulana A. "Effects of Inertia on Long Term Dynamics of a Power System", Department of Electrical Engineering, University of Moratuwa, UG paper, Oct 2004

5. Lucas J.R, Perera H.Y.R, Karunadasa J.P, Wijeypala W.D.A.S. "Report on the Suitability of the limt Placed on a Single Generator unit and the Underutilization of the 300MW Coal unit at Norochchloai"- Submitted to the Honorable Minister of Power and Energy, Sri Lanka, 9th August 2010.

6. "Long Term Transmission Development Plan 2008-2016, Transmission \& Generation Planning Branch, CEB, 2010. 